\title{
Exit-site Infections in Continuous Ambulatory Peritoneal Dialysis Patients, Taif, Saudi Arabia
}

\author{
Khadijah Yousef AL-Aali* \\ Microbiology Department, Faculty of Medicine, Taif University, Taif, Sudia Arabia \\ *Corresponding author
}

\section{Keywords}

Exit-site infection, ESI, infection;

Peritonitis, Microbiology, Peritoneal dialysis,

Taif.

\section{Article Info}

Accepted:

22 March 2016

Available Online:

10 April 2016

\section{A B S T R A C T}

Peritonitis is the most common infectious complication seen in peritoneal dialysis (PD).exit site infection has been thought to predispose PD patients to peritonitis Aim: to assesses exit-site infections in continuous ambulatory peritoneal dialysis patients, Taif, Saudi Arabia. Method: A total 150 patients on peritoneal dialysis were enrolled in this study, in Al-Hada Military Hospital Taif, Saudi Arabia, during the 5 months period from August to December 2015.Swabs were taken and processing under standard method. The age include from 35-60 years. Statistical analyses were performed using the SPSS. Result: Bacteria were grown from $51(33.9 \%)$ of the 150 exit site swabs taken. There is statistical significant difference between Sex/ gender and ESIs, in peritoneal dialysate patients, female $70(46.6 \%) \mathrm{P} 0.04$, while grade $3 P 0.04$, and in 56-60 year $40(26.6 \%) P$ 0.04. The most commonly isolated organisms are, Staphylococcus aureus 15 (29.4\%), MRSA 6(11.7\%), E.coli 12(23.5\%), Pseudomonas aeruginosa 9(17.6\%). Acinetobacter baumannii 3 (5.8\%), and Serratia marcescens 6(11.7\%). The susceptibility pattern of bacteria isolated against 23 antimicrobial agents. All strains were susceptible to some antibiotic, resistance was observed in some strains.Conclusion :This study highlights the need for permanent evaluation by nurses on PD procedure performed by patients, family members, such as proper hand hygiene and hygiene of the skin near the insertion of the catheter.

\section{Introduction}

Peritonitis is a leading cause of technique failure and morbidity in patients undergoing renal replacement therapy with peritoneal dialysis (PD) (1,2). Although the frequency of peritonitis has decreased over the past decade due to improvements in connectology, PD peritonitis still accounts for approximately one-third of all technique failures on PD (3). It is generally accepted that exit site infections (ESIs) may directly lead to peritonitis. The suggested mechanism includes a movement of bacteria from the exit site into the peritoneum via peri-luminal migration along the PD catheter tunnel. Although topical antibacterial agents can prevent ESI and reduce peritonitis rates, there is limited evidence exploring the relationship between ESI and subsequent peritonitis. Furthermore, the specific risk of peritonitis related to different classes of bacterial pathogens remains unknown (4). 
ESI in the immediate post-catheter implantation period may depend on surgical procedures, bacterial colonization, and trauma. Later ESIs occur almost unpredictably, possibly related to mechanical irritation, hypersensitivity to silicone rubber, hyperhydrosis, or reduced tissue reactivity (5). The infection can migrate to the outer and inner cuffs, spread to the peritoneal cavity, and lead to tunnel infection, peritonitis, and even catheter $\operatorname{loss}(6)$.

During the 1990s, the overall probability of developing an ESI was $33 \%-46 \%$ at 1 year and $59 \%-70 \%$ at 3 years on continuous ambulatory PD (CAPD). Peritonitis induced by an ESI is found in $30 \%-50 \%$ of patients, and catheter loss may be as high as $15 \%-57 \% \quad(7,8)$.Systematic reviews demonstrated that the method of implantation, type of catheter, specific exitsite care protocol, and mode of dialysis (CAPD, automated PD (APD)) did not significantly influence peritonitis or ESI rates (9). But mupirocin prophylaxis led to a $63 \%$ reduction in the risk of infection with Staphylococcus aureus, with peritonitis being reduced by $66 \%$ and ESIs by $62 \%$ (10). The bacteria colonizing the exit site are the same as those responsible for exit-site infections, but somewhat different from those causing peritonitis (11).

In a peritoneal dialysis population receiving no antimicrobial prophylaxis, approximately one-half of healthy exit sites are colonized by Staphylococcus aureus, which also accounts for over $50 \%$ of exit-site infections., Staphylococcus epidermidis 20\%, Pseudomonas aeruginosa 8\%, and Escherichia coli 4\%.Nasal carriage of $S$. aureus, common among patients undergoing peritoneal dialysis, also increases the risk of recurrent exit-site infections (12).

With the widespread usage of prophylactic antimicrobial applications at the exit site, there has been a change in the organisms leading to exit-site infections. In a study using gentamicin cream at the exit site (13), the causes of exit-site infection were $S$. aureus in 33\%, other Gram-positive organisms in $27 \%$, yeast in $20 \%$, sterile culture in $13 \%$, and Gram-negative organisms in 7\%.Innovations in connectology and exit-site bacterial prophylaxis have led to a reduced incidence of both peritonitis and exit-site infections in patients on peritoneal dialysis. However, exit-site infections are still a source of morbidity in these patients, and the rate of exit-site infections parallels the rate of patient transfer from peritoneal dialysis to hemodialysis.

The International Society for Peritoneal Dialysis (ISPD) has recommended that the targeted rates for $S$. aureus-related catheter infections be less than 0.05 episodes/patient year at risk, with an overall catheter infection rate of 0.2 episodes per patient year at risk or less (14). These pathogens demonstrate inducible beta-lactamase during initial therapy, potentially leading to empirical regimen failure, prolonged peritoneal damage, and worse outcomes (15). In the ANZDATA registry, the SPICE group of pathogens accounts for $26.9 \%$ of all non-Pseudomonas GNB PD-associated peritonitis, and Acinetobacter species are responsible for, $20 \%$ of these cases $(16,17)$. Intuitively thinking, patients with Acinetobacter PD associated peritonitis might have poorer prognoses compared with the other Enterobacteriaceae members, owing to their high antibiotic resistance rates. However, past reports suggested just the opposite, with technique failure rates of $9 \%$ (18) and 9.2\% (19) in several studies. In addition, several researchers proposed that Acinetobacter peritonitis might occur with an immunocompromised status (20). These reports were all published nearly 2 decades 
ago, and the temporal changes of clinical characteristics, microbiologic features, and outcomes of patients with Acinetobacter PD peritonitis are unknown.

ESI with Pseudomonas is recognized as a major complication of PD, with high risk of catheter loss due to refractory/recurrent infection or peritonitis. Felix et al. 2015 (21) found Pseudomonas responsible of ESI $135(10.3 \%)$.There is remarkably little literature about treatment outcomes in patients with Pseudomonas ESI and there is no standard treatment protocol. The reported cure rate of Pseudomonas ESI with different systemic antibiotic treatment regimens ranges from 42 to $83 \%$ (22-23). Antimicrobial prophylaxis is recommended in addition to the normal daily exit-site care. This approach likely works in part by decreasing the number of potentially pathogenic bacteria that colonize the exit site; so, if trauma occurs, there are few bacteria that can cause tissue invasion and an infection. Antimicrobial prophylaxis requires both a patient-oriented and centeroriented approach (24).

International Society for Peritoneal Dialysis guidelines advise the use of one to two systemic antibiotics in case of Pseudomonas ESI (25). There are no data or recommendations about any topical treatment of Pseudomonas ESI.

Bernardini et al. (26) showed that topical prophylaxis at the exit site with gentamicin results in an equal reduction of ESI with Gram-positive organisms compared with mupirocin and also a reduction in ESI with Gram-negative organisms including Pseudomonas. The aim of the present study was to study the exit-site infections in continuous ambulatory peritoneal dialysis patients, Taif, Saudi Arabia

\section{Materials and Methods}

\section{Study Population}

This study included 150 patients on peritoneal dialysis were enrolled in this study, in Al-Hada Military Hospital Taif, Saudi Arabia, during the 5 months period from August 2015 to December 2015, suffering various forms of Exit site infection (SSIs).Official approval from directors of the hospital has been obtained, after clarification of the aim of the study and assuring the confidentiality to them.

\section{Specimen Collection}

Two Swabs from peritoneal catheter exitsites were taken. The skin close to the exitsite of the catheter was also swabbed in a circular manner. Both swabs were placed in Stuart's transport medium (Culturette system, Becton Dickinson, Cockeysville, MD, USA) and sent to the microbiological laboratory. Immediately, swabs were plated onto both 5\% blood, McConkey, Chocolate agar, Sabourad Dextrose Agar(SABDEX), Saudi Prepared Media Laboratory, Saudi Arabia, Riyadh (SPML), and incubated aerobically at $37^{\circ} \mathrm{C}$ for $18-24 \mathrm{~h}$,

The demographic data of the patients and the diagnostic criteria were collected by the treating dialysis team. Other data including associated risks factors (i.e. diabetes, obesity, steroid therapy), use of prophylactic antimicrobial agents, the type and duration of dialysis, clinical evaluation of wound (considered infected if there was pus discharge or redness and swelling with fever), and laboratory data (including Gram stain, culture results, identification of the bacterial isolates as well as antimicrobial susceptibility) were recorded on a data sheet. 


\section{Sample Processing}

Direct examination of specimens: The first swab was used to prepare two direct smears. One was examined after adding $10 \% \mathrm{KOH}$ solution for fungal identification. The other was stained by Gram stain for bacterial examination and detection of PMNL which is an important feature in case of bacterial infection rather than in bacterial colonization. Plates were incubated at $37^{\circ} \mathrm{C}$ for $48 \mathrm{~h}$. Bacteria were identified by means of standard laboratory identification methods. Oxacillin resistance testing was performed for Staphylococcus aureus isolates by use of oxacillin screen agar (Saudi Prepared Media Laboratory, Saudi Arabia, Riyadh (SPML). For each sample, total bacterial counts were enumerated, and the 3 most prevalent organisms were recorded, in order of density.

\section{Species Identification}

Bacterial growths yields was identified according to standard conventional procedures :

The species identification was based on Gram-stain, catalase test, oxidase test, indole test, staphyloslide test kit (BBL Staphyloslide), sugar assimilation test, sugar fermentation test.

Identified isolates were stored on nutrient agar slant at room temperature for subsequent susceptibility testing.

Commercial identification kits were used to identify the isolates up to species level Different type of API kits (Analytab product, Plainview, N.Y), and Vitek system, different card for identification of Gram-positive bacteria, Gram-negative bacteria, yeast (bioMérieux, Inc. Durham NC,USA).
Afterwards, the sensitivity to the antibiotics was accomplished by disk diffusion test performed for all the isolates by the method recommended by Clinical and Laboratory Standard Institute (CLSI). A suspension of each isolate was made so that the turbidity was equal to 0.5 McFarland turbidity standard and then plated onto Muller-Hinton agar (Saudi Prepared Media Laboratory, Saudi Arabia, Riyadh (SPML).Antibiotic disks (Oxoid) were applied to each plate. After incubation at $37^{\circ} \mathrm{C}$ for $24 \mathrm{~h}$, inhibition zone size was measured. The patients received the proper antibiotic thereafter. Twenty three types of antibiotics were used in both Gram-negative rod,and Grampositive cocci; Amoxicillin/ Clavulinicacid $(20 / 10 \mu \mathrm{g}), \quad$ Cephalotin $(30 \mu \mathrm{g})$, Oxacillin $(1 \mu \mathrm{g}), \quad$ Gentamicin $\quad(10 \mu \mathrm{g})$, Sulfamethoxazole/ Trimethoprim $(1.25 / 23.75 \mu \mathrm{g}), \quad$ Ciprofloxacin $(5 \mu \mathrm{g})$, Clindamycin $(2 \mu \mathrm{g}), \quad$ Vancomycin $(30 \mu)$,

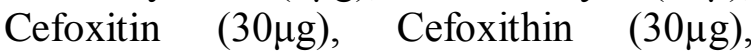
Ceftazidime $(30 \mu \mathrm{g}), \quad$ Cefotaxime $(30 \mu \mathrm{g})$, Amikacin $(30 \mu \mathrm{g})$, Ceftriaxone $(30 \mu \mathrm{g})$, Ceftazidime $(30 \mu \mathrm{g})$, Ampicillin/Sulbactam

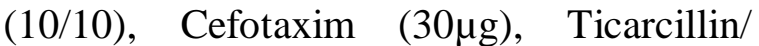
clavulanicacid $\quad(75 / 10 \mu \mathrm{g}), \quad$ Imipenem $(50 \mu \mathrm{g}))$, Cefepime $(10 \mu \mathrm{g}), \quad$ Ampicillin/ Sulbactam $(10 / 10 \mu \mathrm{g})$, Aztreonam $(30 \mu \mathrm{g})$, Piperacillin/ tazobactam $(100 / 10 \mu \mathrm{g})$.

\section{Quality Control}

To maintain the quality of data every sample was processed in triplicates and every result was cross checked by the principal investigator. Enterococcus faecalis (ATCC 29212), Staphylococcus aureus (ATCC 24923), Streptococcus pyogenes (ATCC 19615), E.coli (ATCC 25922), Pseudomonas aeruginosa (ATCC 27853) were used as quality control throughout the study for culture, Gram stain. All the strains were obtained from the (ATCC, The essential of live science research, USA) 


\section{Data Analysis}

Statistical analyses were performed using the Statistical Package for the Social Science (SPSS), Version 16 for Windows. Continuous variables were summarized using descriptive statistics in terms of means, \pm standard deviations, T.test; $95 \%$ confidence intervals $(95 \% \mathrm{CI}), \mathrm{P}$ value < 0.05 were considered significant.

\section{Results and Discussion}

This study included 150 patients, 10 child/boy (4.6\%), 10 chilled /girl (4.6\%), adult/male 90 (41.4\%), adult/female 107 (49.3\%),their ages ranged from 35 years to 60 years. 51samples were positive for culture 51(33.9\%), and 99(65.4\%) was negative growth.

Bacteria were grown from 51(33.9\%) of the 150 exit site swabs taken; Male 80(53.3\%), while female 70 presented in rate of (46.6\%). Bacterial growth in ES swabs was isolated from $51(33.9 \%)$ of these (Table 2). In grade $0 / 1$ exit-site infections, bacteria was isolated 11 times $(7.3 \%)$ of 150 swabs taken, in grade 2 positive culture was found in $24(16 \%)$, while grade 3 , and 4 were presented in low rate of $10(6.6 \%), 6(4 \%)$, respectively (Table 2).There was no enrollment restriction based on age, gender, end-stage renal diseases or previous renal replacement therapy. There is statistical significant difference between Sex/ gender and ESIs, in peritoneal dialysate patients, female $70(46.6 \%) P 0.04$.

The grade of positive catheter-exit-site infection was categorized independently from the microbiological results following the ES-grade bacterial growth in ES swabs. The total positive culture $51(33.9 \%)$ out of 150 samples. The grade 2 presented in high range was24 (16\%), while grade 0/1 followed $11(7.3 \%)$. In contrast grade 3,4 found in low percentage of $10(6.6 \%), 6$ (4\%) respectively. Table 2.There is statistical significant difference between bacterial growth in ES swabs and ESIs, in peritoneal dialysate patients in grade 3 , P0.04.

The main group of the patient at peritoneal dialysate patient was at age of 50-55 year $50(33.3 \%)$, flowed 56-60 year 40(26.6\%), while the age of 45-49 year gave the rate of 24 (16\%),In contrast age 40-44, and 35-39 year presented in the percentage of $20(13.3 \%), 16(10.5 \%)$, respectfully. There is statistical significant difference between age in years in ESIs patient at 56-60 year 40(26.6\%) P 0.04 .

The grade of catheter-exit-site infection was categorized independently from the microbiological results following the ESgrade bacterial growth in ES swabs. Total classification of Twardowski (13), Table4.The physician on duty during each ambulatory visit documented the clinical grading of infection in the patient's records. Exit-site infection Positive Negative grades 2, 3 and 4 were treated with local aseptic ointment and intravenous antibiotic (vancomycin) was given for exit site infection grades 3 and 4 . Swabs were taken before and 2 weeks after the end of the antiseptic and/or antibiotic treatment.

Bacteria were grown from 51(33.9\%) of the 150 exit site swabs taken;

Staphylococcus aureus predominant bacteria $15(29.4 \%)$, in grade $2,(7,46.6 \%)$, while in grade $0 / 1(4,26.6 \%)$, and in grade 3 , and 4 presented in same range of $(13.3 \%)$

MRSA flowed in $6(11.7 \%)$ in grade 2 presented in high rate of $(3,50 \%)$, while in grade $0 / 1,3$, and 4 presented in same range of $1(16.5 \%)$ 
E.coli isolated 12times $(23.5 \%)$ in grade 2 presented in high rate of $7(58.3,50 \%)$, while in grade $0 / 1,3$, and 4 presented in low range of $2(16.6 \%), 1(8.3 \%)$, respectively.

Pseudomonas aeruginosa isolated 9 times $17.6 \%$, in grade 2 presented in high rate of $4(44.4 \%)$, while in grade $0 / 1,3$, and 4 presented in low range of $2(22.2 \%), 1$ $(11.1 \%)$, respectively.

Acinetobacter baumannii isolated 3 times $5.8 \%$, in grade $0 / 1,2,3$ presented in the same rate of $1(33.3 \%)$, and not isolated from grade 4.

Serratia marcescens isolated 6 times $11.7 \%$, in grade 2 presented in high rate of $3(33.3 \%)$, while in grade $0 / 1$, and 4 presented in low range of 1(16.6\%). Table 5. Fig1.

\section{Antibiotic Sensitivity}

Disk diffusion method was performed to all bacterial isolates causing infection. Among these isolates, many were found to be resistant to more than one antibiotic. The susceptibility pattern of bacteria isolated from ESIs patient against 23 antimicrobial agents Table 5,6,7.

Staphylococcus aureus found to be resistant in 15 out of 99 cases representing $29.4 \%$. The result of this study revealed that, resistant of Staphylococcus aureus to 15 antibiotic, and fully susceptible to oxacillin, vancomycin, and penecillin. All strains were susceptible to some antibiotic used in study, and resistance was observed in some strains of Staphylococcus aureus, the different isolates' resistance to various antibiotics in percent study (Table 5). The antimicrobial susceptibility pattern of MRSA isolates against antimicrobial agents are summarized in Table 6.More than 6(100\%) of MRSA isolates were resistant to oxacillin, co- trimoxazole, gentamicin, amikacin, ciprofloxacin, ceftriaxone, ceftazidime, ampicillin/ sulbactam, Amoxicillin/ Clavulanic acid, Penicillin, Cephalothin. Al stains showed sensitive to vancomycin, clindamycin,

E.coli found to be resistant in 12 out of 51 cases representing $23.5 \%$, while Pseudomonas aeruginosa9 (17.6\%). In contrast Acinetobacter baumannii found to be resistant in 3(5.8\%), and Serratia marcescens was resistant to $6(11.7 \%)$. E.coli was fully sensitive to ceftriaxone, imipenem, and cefepime, while Pseudomonas aeruginosa was sensitive to ccefoxithin, amikacin, ciprofloxacin, ceftriaxone, ampicillin/ sulbactam, ticarcillin/clavulanic acid, Acinetobacter baumannii, and Serratia marcescens, were sensitive to both antibiotics imipenem, and cefepim.

ESI should be considered with the development of rash at the PD catheter exit site ESI is a major risk factor for the development and treatment of ESI are essential (28).Skin infection at the catheter exit site remains a relevant problem in PD patients. Peritonitis episodes are usually easily identified and counted, but exit sites vary broadly in appearance from uninfected to infected, making for a wide variation in ESI classification and treatment between PD units. This variation leads to imprecise definitions of ESI, inconsistent monitoring, and difficulties in interpreting study results. In trying to avoid these difficulties, we considered ESI only when signs of infection were present and cultures were available (29). The difficulty in microbiologic ESI diagnosis is highlighted in that regional commensal flora is often reported in clinically evident ESIs. Total samples enrolled in this study was 150.The incidence of ESI in the present study was 51(333\%), 
which is higher than reported worldwide incidence of Burkhard et al (30) on exit site infections which reported, bacteria were grown from 99 (26\%).

The result of present study revealed that, Staphylococcus aureus predominant bacteria 15(29.4\%), E.coli followed in isolated 12(23.5\%), while Pseudomonas aeruginosa isolated 9 times (17.6\%). In contrast MRSA, Serratia marcescens, Acinetobacter baumannii were presented in the same low rate of $6(11.7 \%)$.This result was in agreement with the finding reported by Burkhard et al (30), who found that, rate of ESI was higher in grade 0/1 exit-site infections, S. aureus isolates was isolated $15(20 \%)$, and in pared with strains isolated in lower infectious grades grade 2, 3 and 4, S. aureus was found in 10 swabs (40\%).

In other study, in adults, previously reported ESI rates range from $0.05-1.02$ episodes/patient-year. In contrast, Grampositive agents were responsible for most pericatheter infectious episodes, and $S$. aureus (at a rate of 0.46 per dialysis year at risk) was the primary cause of ESIs (31). A study indicated that the main risk factor for the occurrence of catheter exit-site infection is being a nasal staphylococcus carrier. Thereby, it is reinforced the importance of hand hygiene and use of masks by patients and caregivers, while performing peritoneal dialysis procedure (32).

In our study, found that E.coli was the most frequent Gram negative agent 12(23.5\%), followed by $P$. aeruginosa 9(17.6\%), while, $P$. aeruginosa was the most frequent Gram negative agent $(8 \%-12 \%)$, followed by other Enterobacteriaceae (7\% - 14\%).Felix et al.(2015) found that, Pseudomonas ESI in PD patients from 135 patient presented in low range of $14(10.3 \%)$ (21). Chia et al. (2014), found that Acinetobacter baumannii after 2000, was 9 (64\%)was the most common species identified from the effluent, and the leading causes of infection were sterility break and GI microflora translocation (33).

Previous studies have reported that age and longer dialysis duration were not associated with an increase in ESIs (34), but African American and prior renal transplant patients have an increased susceptibility to catheterrelated infections (35). Diabetic and immunosuppressed patients are also at risk for early $S$. aureus ESIs. Patients on automated peritoneal dialysis (APD) were found to have lower rates of peritonitis, but not lower rates of ESIs or tunnel infections. The importance of peritoneal dialysis catheter exit site problems in determining the long-term success of CAPD therapy has recently been receiving increasing attention. Detailed analyses of CAPD technique failures have suggested that approximately (36).

There are limited data available to review with regard to ESI in Saudi Arabian patients. Al-Hwiesh et al.(37), reported that, Grampositive ESI occurred in $17.1 \%$ vs $10.2 \%$ of patients $(\mathrm{p}<0.05)$, whereas $20 \%$ of and $5.1 \%$ of patients $(\mathrm{p}<0.001)$ had Gram-negative ESI in the 2 groups, respectively. While UrRehman et al.(38), found exit-site infections occurred in $17(30 \%)$ patients, Whereas Ghulam et al. (39), reported that, the most common causative organisms for peritonitis were Pseudomonas (16\%), Staphylococcus epidermidis (16\%), and Staphylococcus aureus (7\%).

The International Society for Peritoneal Dialysis (ISPD) recommends cleaning of PD catheter exit site with antiseptic agent and application of topical antimicrobials, such as gentamicin or mupirocin, for the prevention of ESI (14). Topical gentamicin has been 
shown to reduce ESI and peritonitis due to gram-positive and gram-negative organisms, while, topical mupirocin mainly reduced ESI due to gram-positive organisms. ESI is typically diagnosed clinically based on the finding of purulent or bloody drainage from PD catheter exit site, surrounding erythema, tenderness, and swelling. However, the presence of skin rash and erythema without drainage at the PD catheter exit site can be also due to early infection, allergic reaction to PD catheter material, or to mechanical trauma (40).By analyzing the results obtained in relation to sociodemographic variables, it was observed consistency with those found by the Brazilian Society of Nephrology and by a cohort study named BRAZPD, performed in the South and Southeast regions of Brazil(41).The complexity of the peritoneal dialysis procedure is recognized. In this sense, the sociodemographic variables must be considered in establishing the diagnosis of cognitive, motor and affective skills of the patients and/or caregivers by the nurses, in order to prevent infectious complications in PD (42).

Table.1 Socio-demographic Characteristics (Sex, Gender) of Patient at Peritoneal Dialysate,Taif, $\mathrm{N}=150$

\begin{tabular}{|l|l|l|l|}
\hline $\begin{array}{l}\text { Socio-demographic } \\
\text { Characteristics } \\
\text { Sex/gender }\end{array}$ & $\begin{array}{l}\text { Frequency } \\
N=150\end{array}$ & $\%$ & $P$ value \\
\hline Male & 80 & 53.3 & \\
\hline Female & 70 & 46.6 & 0.04 \\
\hline Total & 150 & 100 & \\
\hline Mean $1.5 / 75 ;$ Std +0.707 & & & \\
\hline
\end{tabular}

Table.2 Results of Bacterial Cultures from Exit-site (ES) Swabs (N=150)

\begin{tabular}{|l|l|l|l|}
\hline \multirow{2}{*}{ ES-grade } & \multicolumn{2}{|l|}{ Bacterial growth in ES swabs (\%) } & \multirow{2}{*}{ Total } \\
\cline { 2 - 3 } & Positive & Negative & \\
\hline $0 / 1$ & $11(7.3 \%)$ & $20(13.3 \%)$ & $31((20.6 \%)$ \\
\hline 2 & $24(16 \%)$ & $45(30 \%)$ & $69(46 \%)$ \\
\hline 3 & $10(6.6 \%) P 0.04$ & $14(9.3 \%)$ & $24(16 \%)$ \\
\hline 4 & $6(4 \%)$ & $20(13.3 \%)$ & $26(17.3 \%)$ \\
\hline Total & $51(33.9 \%)$ & $99(65.9 \%)$ & $150(100 \%)$ \\
\hline
\end{tabular}

Table.3 Socio-demographic Characteristics (Age in Years) of Patient at Peritoneal Dialysate, Taif, $\mathrm{N}=150$

\begin{tabular}{|c|c|c|c|}
\hline $\begin{array}{l}\text { Socio-demographic } \\
\text { Characteristics }\end{array}$ & $\begin{array}{l}\text { Frequency } \\
\mathrm{N}=150\end{array}$ & Percent (\%) & $P$ value \\
\hline 1- Age in years & & & \\
\hline $35-39$ & 16 & 10.5 & \\
\hline $40-44$ & 20 & 13.3 & \\
\hline $45-49$ & 24 & 16 & \\
\hline $50-55$ & 50 & 33.3 & \\
\hline $56-60$ & 40 & 26.6 & $P 0.04$ \\
\hline Total & 150 & 100 & \\
\hline Mean 3/30; Std $+1.5 / 14.4$ & & & \\
\hline
\end{tabular}


Table.4 Clinical Grading of Exit-site Appearance (ES 0-4), According to ref. (27 )

\begin{tabular}{|l|l|l|l|l|l|}
\hline ES & Redness & Swelling & Pain & Secretion & Pus \\
\hline 0 & no & no & no & no & no \\
\hline 1 & $<2 \mathrm{~mm}$ & no & no & no & no \\
\hline 2 & $<2 \mathrm{~mm}$ & no & no & + & + \\
\hline 3 & $<2 \mathrm{~mm}$ & yes & Yes & ++ & ++ \\
\hline 4 & $<2 \mathrm{~mm}$ & yes & yes & +++ & +++ \\
\hline
\end{tabular}

ES: Exit-site,+: present, ++: moderate, +++: intense

Table.5 Results of Positive Bacterial Cultures (N=150)

\begin{tabular}{|c|c|c|c|c|c|c|}
\hline \multicolumn{7}{|c|}{ Positive ES swab (\%) } \\
\hline $\begin{array}{l}\text { ES- } \\
\text { grade }\end{array}$ & $\begin{array}{l}\text { Staphylococcus } \\
\text { aureus } \\
\text { N.15(29.4\%) }\end{array}$ & $\begin{array}{l}\text { MRSA } \\
N .6(11.7 \%)\end{array}$ & $\begin{array}{l}\text { E.coli } \\
\text { N.12(23.5\% }\end{array}$ & $\begin{array}{l}\text { Pseudomonas } \\
\text { aeruginosa } \\
N .9(17.6 \%\end{array}$ & $\begin{array}{l}\text { Acinetobacter baumannii } \\
N .3(5.8 \%)\end{array}$ & $\begin{array}{l}\text { Serratia marcescens } \\
\text { N.6(11.7\%) }\end{array}$ \\
\hline $0 / 1$ & $4(26.6 \%)$ & $1(16.6 \%)$ & $2(16.6 \%)$ & $2(22.2 \%)$ & $1(33.3 \%)$ & $\begin{array}{l}1(16.6 \%) \\
\mathrm{P} 0.01\end{array}$ \\
\hline 2 & $7(46.6 \%)$ & $3(50 \%)$ & $7(58.3 \%)$ & $4(44.4 \%)$ & $1(33.3 \%)$ & $2(33.3 \%)$ \\
\hline 3 & $\begin{array}{l}2(13.3 \%) \\
\mathrm{P} 0.03\end{array}$ & $\begin{array}{l}1(16.5 \%) \\
\text { P } 0.03 \\
\text { P } 0.05\end{array}$ & $\begin{array}{l}2(16.6 \%) \\
\text { P } 0.03\end{array}$ & $\begin{array}{l}2(22.2 \%) \\
\mathrm{P} 0.03\end{array}$ & $1(33.3 \%)$ & $2(33.3 \%)$ \\
\hline 4 & $2(13.3 \%)$ & $1(16.5 \%)$ & $1(8.3 \%)$ & $1(11.1 \%)$ & $\mathrm{NI}$ & $1(16.6 \%)$ \\
\hline Total & 15 & 6 & 12 & 9 & 3 & 6 \\
\hline
\end{tabular}

Table.6 Antibiotic Susceptibility Pattern (\%) of Resistant Staphylococcus aureus, and MRSA Isolates in ESI Patients

\begin{tabular}{|l|l|l|}
\hline Antibiotics & $\begin{array}{l}\text { Resistant } \\
\text { Staphylococcus } \\
\text { aureus } \\
\text { N=15(29.4\%) }\end{array}$ & $\begin{array}{l}\text { Resistant } \\
\text { MRSA } \\
\text { N=6 }(11.7 \%)\end{array}$ \\
\hline $\begin{array}{l}\text { Amoxicillin/ Clavulanic acid } \\
(20 / 10 \mu \mathrm{g})\end{array}$ & $3(20 \%)$ & $6(100 \%)$ \\
\hline Cephalothin $(30 \mu \mathrm{g})$ & $2(13.3 \%)$ & $5(83.3)$ \\
\hline Oxacillin $(1 \mu \mathrm{g})$ & $* \mathrm{~S}$ & $6(100 \%)$ \\
\hline Gentamicin $(10 \mu \mathrm{g})$ & $3(20 \%)$ & $6(100 \%)$ \\
\hline Amikacin $(30 \mu \mathrm{g})$ & $2(13.3 \%)$ & $6(100 \%)$ \\
\hline Ciprofloxacin $(1 \mu \mathrm{g})$ & $1(6.6 \%)$ & $6(100 \%)$ \\
\hline Ceftriaxone $(30 \mu \mathrm{g})$ & $1(6.6 \%)$ & $6(100 \%)$ \\
\hline Co-trimoxazole $(1.2 / 23.8 \mu \mathrm{g})$ & $5(33.3 \%)$ & $6(100 \%)$ \\
\hline Ceftazidime $(30 \mu \mathrm{g})$ & $3(20 \%)$ & $6(100 \%)$ \\
\hline Ampicillin/Sulbactam $(10 / 10)$ & $2(13.3 \%)$ & $6(100 \%)$ \\
\hline Penicillin $(\mathrm{unit})$ & $\mathrm{S}$ & $6(100 \%)$ \\
\hline Vancomycin $(30 \mu \mathrm{g})$ & $\mathrm{S}$ & $\mathrm{S}$ \\
\hline Clindamycin $(2 \mu \mathrm{g})$ & $\mathrm{S}$ & $\mathrm{S}$ \\
\hline
\end{tabular}

*S; sensitive 
Table.7 Antibiotic Susceptibility Pattern (\%) of Resistant Gram-Negative Isolates in ESI Patients

\begin{tabular}{|l|l|l|l|l|}
\hline Antibiotics & $\begin{array}{l}\text { Resistant } \\
\text { E.coli } \\
\mathrm{N}=12 \\
(23.5 \%)\end{array}$ & $\begin{array}{l}\text { Resistant } \\
\text { Pseudomonas } \\
\text { aeruginosa } \\
\mathrm{N}=9(17.6 \%)\end{array}$ & $\begin{array}{l}\text { Resistant } \\
\text { Acinetobacter } \\
\text { baumannii } \\
\mathrm{N}=3(5.8 \%)\end{array}$ & $\begin{array}{l}\text { Serratia } \\
\text { marcescens } \\
\text { N.6 }\end{array}$ \\
\hline Aztreonam $(30 \mu \mathrm{g})$ & $1(8.3 \%)$ & $1(11.1 \%)$ & $2(66.6 \%)$ & $1(16.6 \%)$ \\
\hline Cephalothin $(30 \mu \mathrm{g})$ & $3(25 \%)$ & $2(22.2 \%)$ & $3(100 \%)$ & $3(50 \%)$ \\
\hline Cefoxithin $(30 \mu \mathrm{g})$ & $1(8.3 \%)$ & $\mathrm{S}$ & $3(100 \%)$ & $2(33.3 \%)$ \\
\hline Gentamicin $(10 \mu \mathrm{g})$ & $2(16.6 \%)$ & $3(33.3 \%)$ & $2(66.6 \%)$ & $1(16.6 \%)$ \\
\hline Amikacin $(30 \mu \mathrm{g})$ & $1(8.3 \%)$ & $\mathrm{S}$ & $1(4 \%)$ & $3(50 \%)$ \\
\hline Ciprofloxacin $(5 \mu \mathrm{g})$ & $1(8.3 \%)$ & $\mathrm{S}$ & $2(66.6 \%)$ & $1(16.6 \%)$ \\
\hline Ceftriaxone $(30 \mu \mathrm{g})$ & $* \mathrm{~S}$ & $\mathrm{~S}$ & $2(66.6 \%)$ & $2(33.3 \%)$ \\
\hline $\begin{array}{l}\text { Co-trimoxazole } \\
(1.2 / 23.8 \mu \mathrm{g})\end{array}$ & $4(33.3 \%)$ & $2(22.2 \%)$ & $3(23.8 \%)$ & $5(83.3 \%)$ \\
\hline Ceftazidime $(30 \mu \mathrm{g})$ & $2(16.6 \%)$ & $1(11.1 \%)$ & $1(4.7 \%)$ & $2(33.3 \%)$ \\
\hline $\begin{array}{l}\text { Ampicillin/Sulbactam } \\
(10 / 10 \mu \mathrm{g})\end{array}$ & $1(8.3 \%)$ & $\mathrm{S}$ & $1(4.7 \%)$ & $1(16.6 \%)$ \\
\hline Cefotaxim $(30 \mu \mathrm{g})$ & $3(25 \%)$ & $1(11.1 \%)$ & $2(66.6 \%)$ & $1(16.6 \%)$ \\
\hline $\begin{array}{l}\text { Ticarcillin/clavulanic acid } \\
(75 / 10 \mu \mathrm{g})\end{array}$ & $2(16.6 \%)$ & $\mathrm{S}$ & $2(66.6 \%)$ & $2(33.3 \%)$ \\
\hline $\begin{array}{l}\text { Piperacillin/tazobactam } \\
(100 / 10 \mu \mathrm{g})\end{array}$ & $1(8.3 \%)$ & $1(11.1 \%)$ & $2(66.6 \%)$ & $1(16.6 \%)$ \\
\hline Imipenem $(10 \mu \mathrm{g})$ & $\mathrm{S})$ & $\mathrm{S}$ & $\mathrm{S}$ & $\mathrm{S}$ \\
\hline Cefepime $(10 \mu \mathrm{g})$ & $\mathrm{S}$ & $\mathrm{S}$ & $\mathrm{S}$ & $\mathrm{S}$ \\
\hline
\end{tabular}

*S; sensitive

Fig.1 Frequency Distribution of Bacteria Isolated from Exit Site

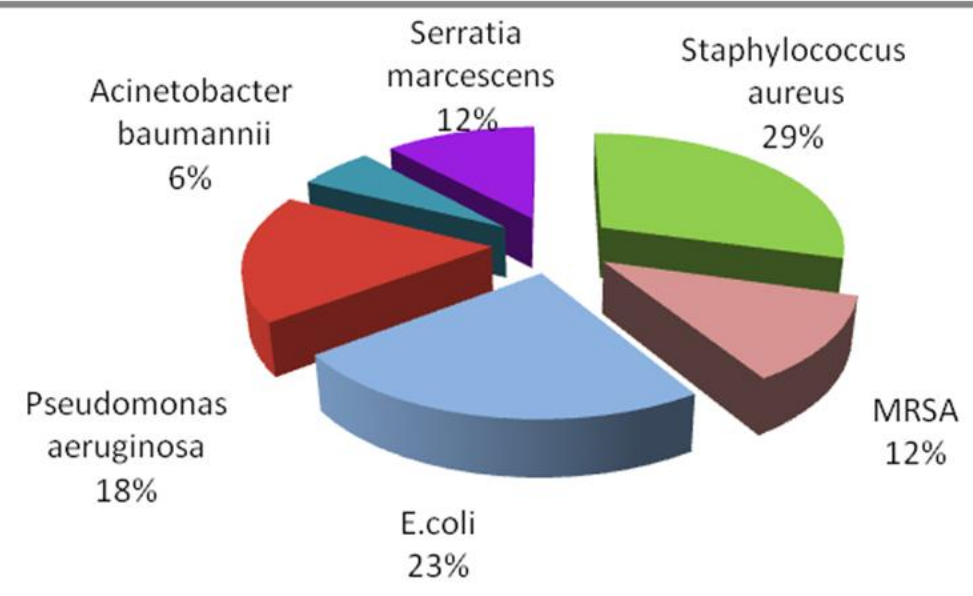

The results obtained in this study showed that, $33.9 \%$ of patients were admitted to the dialysis program with a primary diagnosis of unspecific kidney disease (43).This result shows that, at the study site, the number of patients on PD knowledge of the primary disease is high. This may reflect the time spent by the patient waiting for the first medical consultation. In a study by Lo et al. (44), $40.2 \%$ of ESI episodes were caused by $P$. aeruginosa, and early removal of the catheter was recommended. Kazmi et al. (45) noted that, of 18 episodes of ESI caused by $P$. aeruginosa, $15(83 \%)$ resolved with antibiotic therapy; only $3(17 \%)$ required catheter removal. 
All isolates of $S$. aureus, and MRSA were sensitive to oxacillin, vancomycin, clindamycin, also found resistant in some strains. Table 6 .Vancomycin remains the first choice of treatment for MRSA and to preserve its value, vancomycin use should be limited to those cases where there are clearly needed (46). The susceptibility testing of the Gram-negative organisms; $E$. coli showed that higher resistant to, cotrimoxazole, cefotaxime, while Pseudomonas aeruginosa resistant to cephalothin, gentamicin. In contrast, Acinetobacter baumannii presented and resistant to antibiotics, ciprofloxacin, ceftriaxone, aztreonam, cephalothin, cefoxithin, Ticarcillin/clavulanic acid with high percentage, and Serratia marcescens showed high rate of resistant to cotrimoxazole, cephalothin, cefoxithin, ticarcillin/ clavulanic acid

In conclusion, Continuous ambulatory peritoneal dialysis is a viable therapy option in ESRD patients in Saudi Arabia. Peritonitis and exit-site infection are the main problems encountered, but their prevalence's are comparable to those seen in studies from PD centers in other countries. Eradication of Pseudomonas ESI remains difficult even with the addition of topical gentamicin to the exit site. The ideal systemic antibiotic treatment is still to be determined. There should be a low threshold for catheter replacement in case of unresolved infection, as the risk of occurrence of Pseudomonas peritonitis is high. The maintenance of peritoneal catheter is the patient's responsibility, with the supervision of the healthcare team. The nurses play a key role, since they are responsible for the professional training of patients, families and caregivers. The constant monitoring favors safety for the procedure in $\mathrm{PD}$, in order to reduce future complications and maintain the quality of life of patients.

\section{References}

1.Li PKT, Szeto CC, Piraino B et al. Peritoneal dialysis-related infections recommendations: 2010 update. Perit Dial Int 2010; 30: 393-423

2.Brown F, Liu WJ, Kotsanas D et al. A quarter of a century of adult PD related peritonitis at an Australian medical center. Perit Dial Int 2007; 27: 565-574

3.Jaar BG, Plantinga LC, Crews DC et al. Timing, causes, predictors and prognosis of switching from peritoneal dialysis to hemodialysis: a prospective study. BMC Nephrol 2009; 10

4.Alissa Lloyd, NavdeepTangri, Leigh Anne Shafer, Claudio Rigatto, Jeffrey Perl, Paul Komenda, and Manish M. Sood.The risk of peritonitis after an exit site infection: a time-matched, case-control study. Nephrol Dial Transplant (2013) 1-6

5. Vas SI. Questions, answers.Perit Dial Bull 1981;1:145-6.

6.Cristina Freitas, Anabela Rodrigues, Maria JoãoCarvalho, AntónioCabrita. Exit Site Infections: Systematic microbiologic and quality control are needed. Advances in Peritoneal Dialysis, Vol. 25, 2009

7. Vargemezis V, Thodis E. Prevention and management of peritonitis and exitsite infection in patients on continuous ambulatory peritoneal dialysis. Nephrol Dial Transplant 2001;16(Suppl 6):106-8.

8.Luzar MA. Exit-site infections in continuous ambulatory peritoneal dialysis: a review.Perit Dial Int 1991;11:333-40.

9. Strippoli GF, Tong A, Johnson D, Schena FP, Craig JC. Catheter type, placement and insertion techniques for preventing peritonitis in 
peritoneal dialysis patients. Cochrane Database Syst Rev 2004;18:CD004680.

10. Piraino B, Bernardini J, Bender FH. An analysis of methods to prevent peritoneal dialysis catheter infections.Perit Dial Int 2008;28:437-43.

11.Scalamogna A, Castelnovo C, De Vecchi A, Ponticelli C. Exit-site and tunnel infections in continuous ambulatory peritoneal dialysis patients. Am J Kidney Dis 1991; 18:674.

12. Nouwen JL, Fieren MW, Snijders S, et al. Persistent (not intermittent) nasal carriage of Staphylococcus aureus is the determinant of CPD-related infections. Kidney Int 2005; 67:1084.

13. Bernardini J, Bender F, Florio T, et al. Randomized, double-blind trial of antibiotic exit site cream for prevention of exit site infection in peritoneal dialysis patients. J Am SocNephrol 2005; 16:539-454.

14. Piraino B, Bernardini J, Brown E, et al. ISPD position statement on reducing the risks of peritoneal dialysisrelated infections. Perit Dial Int 2011; 31:614-630.

15. Chao CT, Lee SY, Yang WS, Chen HW, Fang CC, et al (2013) Citrobacter peritoneal dialysis peritonitis: rare occurrence with poor outcomes. Int J Med Sci 10: 1092-1098.

16. Jarvis EM, Hawley CM, McDonald SP, Brown FG, Rosman JB, et al (2010) Predictors, treatment, and outcomes of non-Pseudomonas Gram-negative peritonitis. Kidney Int 78: 408-414.

17. Szeto CC, Leung CB, Chow KM, Kwan BC, Law MC, et al (2005) Change in bacterial aetiology of peritoneal dialysis-related peritonitis over 10 years: experience from a centre in south-east Asia. ClinMicrobiol Infect
11: 837-839.

18.Galvao C, Swartz R, Rocher L, Reynolds J, Starmann B, et al (1989) Acinetobacter peritonitis during chronic peritoneal dialysis. Am J Kidney Dis 14: 101-104.

19.Lye WC, Lee EJ, Ang KK (1991) Acinetobacter peritonitis in patients on CAPD: characteristics and outcome. AdvPerit Dial 7: 176-179.

20. Lye W, Lee EJ, Leong S, Kumarasinghe G (1994) Clinical characteristics and outcome of Acinetobacter infections in CAPD patients. Perit Dial Int 14: 174-177.

21.Felix Burkhalter, Michelle Clemenger, San SanHaddoub,JacquelineMcGrory, Nora Hisole, and Edwina Brown. Pseudomonas exit-site infection: treatment outcomes with topical gentamicin in addition to systemic antibiotics. Clinical Kidney Journal, 2015 , vol. 8, no. 6, 781-784

22.Lo CY, Chu WL, Wan KM et al. Pseudomonas exit-site infections in CAPD patients: evolution and outcome of treatment. Perit Dial Int 1998; 18: 637-640

23.Szabo T, Siccion $\mathrm{Z}$, Izatt $\mathrm{S}$ et al Outcome of Pseudomonas aeruginosa exit-site and tunnel infections: a single center's experience. AdvPerit Dial 1999; 15: 209-212

24. McQuillan RF, Chiu E, Nessim S, et al. A randomized controlled trial comparing mupirocin and polysporin triple ointments in peritoneal dialysis patients: the MP3 Study. Clin J Am SocNephrol 2012; 7:297.

25.Li PK, Szeto CC, Piraino B et al. Peritoneal dialysis-related infections recommendations: 2010 update. Perit Dial Int 2010; 30: 393-423

26. Bernardini J, Bender F, Florio $\mathrm{T}$ et al. 
Randomized, doubleblind trial of antibiotic exit site cream for prevention of exit site infection in peritoneal dialysis patients. J Am SocNephrol 2005; 16: 539-545.

27. Twardowski ZJ. Exit-site-infections. In: La Greca G, RencerC,Ferriani M, eds. Peritonealdialysis. 1991; 241245

28. Piraino B, Bernardini J, Sorkin M. The influence of peritoneal catheter exitsite infections on peritonitis, tunnel infections, and catheter loss in patients on continuous ambulatory peritoneal dialysis. Am J Kidney Dis. 1986;8:436-440.

29.Luzar MA. Exit-site infections in continuous ambulatory peritoneal dialysis: a review. Perit Dial Int 1991;11:333-40.

30.BurkhardKreft, Sandra Ilic, Wilma Ziebuhr, Andreas Kahl, Ulrich Frei, Klaus Sack, Matthias Trautmann. Adherence of Staphylococcus aureus isolated in peritoneal dialysis-related exit-site infections to HEp-2 cells and silicone peritoneal catheter materials. Nephrol Dial Transplant (1998) 13: 3160-3164

31.Jassal SV, Lok CE. A randomized controlled trial comparing mupirocin versus Polysporin Triple for the prevention of catheter-related infections in peritoneal dialysis patients (the MP3 study).Perit Dial Int 2008;28:67-72.

32. Leehey DJ, Szeto C, Li PK. Peritonite e Infecção do Local de Saída. In: Daugirdas JT, Blake PG, Ing TS. Manual de Diálise. 4. ed. Rio de Janeiro: Medsi; 2008. p. 383-404.

33.Chia-Ter Chao, Szu-Ying Lee, Wei-Shun Yang, Huei-Wen Chen, ChengChung Fang, Chung-Jen Yen, ChihKang Chiang, Kuan-Yu Hung, JenqWen Huang. Acinetobacter
Peritoneal Dialysis Peritonitis: A Changing Landscape over Time.PLOSONE. October 2014.Vol. 9(10). e110315 www.plosone.org

34.Holley JL, Bernardini J, Perlmutter JA, Piraino B. A comparison of infection rates among older and younger patients on continuous peritoneal dialysis. Perit Dial Int 1994;14:66-9.

35.Piraino B, Bernardini J, Holley JL, Perlmutter JA. A comparison of peritoneal dialysis-related in shortand long-term peritoneal dialysis patients.Perit Dial Int 1993;13:194-7.

36.Rabindranath KS, Adams J, Ali TZ, Daly C, Vale L, Macleod AM. Automated vs continuous ambulatory peritoneal dialysis: a systematic review of randomized controlled trials. Nephrol Dial Transplant 2007;22:2991-8.

37. Al-Hwiesh AK, Abdul-Rahman IS, AlMuhanna FA, Al-Sulaiman MH, AlJondebi MS, Divino-Filho JC. Prevention of peritoneal dialysis catheter infections in Saudi peritoneal dialysis patients: the emergence of high-level mupirocin resistance. Int J Artif Organs. 2013 Jul;36(7):473-83

38.Ur-Rehman K, Housawi A, Al-Jifri A, Kielar M, Al-Ghamdi S. Peritoneal dialysis for chronic kidney disease patients: a single-center experience in Saudi Arabia. Saudi J Kidney Dis Transpl. 2011 May;22(3):581-6.

39. Ghulam H. Malik, Ali Swaid Al-Harbi, Suleiman A. Al-Mohaya, Raed AlAwaishe, Mohammad C. Kechrid, Akilan Zohair,1 Mohammad S. Shetia, and Osman H. Azhari. Chronic peritioneal dialysis- a single- center experience.PeritDial Int 2003; 23(S2):S188-S191.

40.Wong SS, Chu KH, Cheuk A, et al. 
Prophylaxis against grampositive organisms causing exit-site infection and peritonitis in continuous ambulatory peritoneal dialysis patients by applying mupirocin ointment at the catheter exit site. Perit Dial Int. 2003;23(suppl 2):S153-S158.

41. Sesso RC, Lopes AA, Thomé FS, Lugon JR, Watanabe Y, Santos DR. DiáliseCrônica no Brasil - Relatório do CensoBrasileiro de Diálise, 2011. J Bras Nefrol. 2012;34(3):272-7.

42. Fernandes NMS, Chaoubah A, Bastos K, Lopes AA, Divino-Filho JC, PecoitsFilho R, et al. Geography of peritoneal dialysis in Brazil: analysis of a cohort of 5,819 patients (BRAZPD). J Bras Nefrol. 2010;32(3):265-71.

43.Bernardini J, Price V, Figueiredo A.
Peritoneal dialysis patient training. Perit Dial Int. 2006;26(6):625-32.

44. Lo CY, Chu WL, Wan KM, Ng SY, Lee WL, Chu MF, et al. Pseudomonas exit-site infection in CAPD patients: evolution and outcome of treatment. Perit Dial Int 1998; 18:637-40.

45.Kazmi HR, Raffone FD, Kliger AS, Finkelstein FO. Pseudomonas exit site infection in continuous ambulatory peritoneal dialysis patients. J Am SocNephrol 1992; 2:1498-501.

46.Carlos Wong, In-waLuk, Margaret Ipb,Joyce H.S. You. Prevention of gram-positive infections in peritoneal dialysis patientsin Hong Kong: A cost-effectiveness analysis. American Journal of Infection Control 42 (2014) 412-6

\section{How to cite this article:}

Khadijah Yousef AL-Aali. 2016. Exit-site Infections in Continuous Ambulatory Peritoneal Dialysis Patients, Taif, Saudi Arabia. Int.J.Curr.Microbiol.App.Sci.5(4): 836-849. doi: http://dx.doi.org/10.20546/ijcmas.2016.504.096 